\title{
Partial cell fusion: A newly recognized type of communication between dedifferentiating cardiomyocytes and fibroblasts
}

Citation for published version (APA):

Driesen, R. B. M. A., Dispersyn, G. D., Verheyen, A. K. C. P., van den Eijnde, S. M., Hofstra, L., Thone, F., Dijkstra, P., Debie, W. M. H., Borgers, M., \& Ramaekers, F. C. S. (2005). Partial cell fusion: A newly recognized type of communication between dedifferentiating cardiomyocytes and fibroblasts. Cardiovascular Research, 68(1), 37-46. https://doi.org/10.1016/j.cardiores.2005.05.020

Document status and date:

Published: 01/01/2005

DOI:

10.1016/j.cardiores.2005.05.020

Document Version:

Publisher's PDF, also known as Version of record

Please check the document version of this publication:

- A submitted manuscript is the version of the article upon submission and before peer-review. There can be important differences between the submitted version and the official published version of record.

People interested in the research are advised to contact the author for the final version of the publication, or visit the DOI to the publisher's website.

- The final author version and the galley proof are versions of the publication after peer review.

- The final published version features the final layout of the paper including the volume, issue and page numbers.

Link to publication

\footnotetext{
General rights rights.

- You may freely distribute the URL identifying the publication in the public portal. please follow below link for the End User Agreement:

www.umlib.nl/taverne-license

Take down policy

If you believe that this document breaches copyright please contact us at:

repository@maastrichtuniversity.nl

providing details and we will investigate your claim.
}

Copyright and moral rights for the publications made accessible in the public portal are retained by the authors and/or other copyright owners and it is a condition of accessing publications that users recognise and abide by the legal requirements associated with these

- Users may download and print one copy of any publication from the public portal for the purpose of private study or research.

- You may not further distribute the material or use it for any profit-making activity or commercial gain

If the publication is distributed under the terms of Article $25 \mathrm{fa}$ of the Dutch Copyright Act, indicated by the "Taverne" license above, 


\title{
Partial cell fusion: A newly recognized type of communication between dedifferentiating cardiomyocytes and fibroblasts
}

\author{
Ronald B. Driesen ${ }^{\mathrm{a}, 1}$, Gerrit D. Dispersyn ${ }^{\mathrm{a}, 1}$, Fons K. Verheyen ${ }^{\mathrm{a}, *}$, Stefan M. van den Eijnde ${ }^{\mathrm{a}}$, \\ Leo Hofstra ${ }^{\mathrm{b}}$, Fred Thoné ${ }^{\mathrm{a}}$, Petra Dijkstra ${ }^{\mathrm{c}}$, Wiel Debie ${ }^{\mathrm{a}}$, \\ Marcel Borgers ${ }^{a}$, Frans C.S. Ramaekers ${ }^{a}$ \\ ${ }^{a}$ Department of Molecular Cell Biology, Cardiovascular Research Institute Maastricht (CARIM), University of Maastricht, P.O. Box 616, \\ 6200 MD Maastricht, The Netherlands \\ ${ }^{\mathrm{b}}$ Department of Cardiology, Cardiovascular Research Institute Maastricht (CARIM), University of Maastricht, P.O. Box 616, \\ 6200 MD Maastricht, The Netherlands \\ ${ }^{\mathrm{c}}$ Department of Animal Research and Testing Services, University of Maastricht, P.O. Box 616, 6200 MD Maastricht, The Netherlands
}

Received 18 March 2005; received in revised form 29 April 2005; accepted 18 May 2005

Available online 17 June 2005

Time for primary review 32 days

\begin{abstract}
Objective: Fibroblasts have been shown to couple to neonatal cardiomyocytes in heterocellular cultures through functional gap junctions. Our objective was to provide evidence for an additional type of heterocellular communication between fibroblasts and adult cardiomyocytes in vitro and in vivo.

Methods: The contact areas in heterocellular co-cultures were evaluated by specific labeling and the intercellular communication was studied using preloading of fibroblasts with tracer molecules. Heterocellular fibroblast-cardiomyocyte contacts present in the in vitro setting and in the border zone of a rabbit myocardial infarction in vivo were further examined by electron microscopy.

Results: Addition of fibroblasts preloaded with the fluorescent low molecular weight tracer calcein-AM to cultured myocytes indicated early dye transfer via connexin 43 functional gap junctions. At a later time-period after co-culturing, dye transfer of fibroblasts preloaded with the high molecular weight tracer dextran 10,000 suggested partial cell fusion. The membrane continuity giving rise to this partial cell fusion was confirmed by electron microscopy, clearly showing areas of intercytoplasmic contacts between fibroblasts and phenotypically adapted (dedifferentiated) cardiomyocytes. Fluorescein-labeled annexin V affinity studies revealed transient exposure of phosphatidylserine at the contact sites, suggesting that phosphatidylserine mediates the fusion process. Close contacts between cardiac fibroblasts and dedifferentiated cardiomyocytes accompanied by disruption of the basal lamina were observed in the border zone of a rabbit myocardial infarction in vivo.

Conclusion: Our results suggest that the partial cell fusion-type of heterocellular communication in our co-culture model and the contacts observed in vivo may lead to new insights in cardiovascular disease.
\end{abstract}

(C) 2005 European Society of Cardiology. Published by Elsevier B.V. All rights reserved.

Keywords: Cell communication; Cardiomyocytes; Fibroblasts; Gap junctions; Partial cell fusion; Annexin V

This article is referred to in the Editorial by Lamers and Köhler (pages 1-2) in this issue.

\footnotetext{
* Corresponding author. Tel.: +31 43 3881354; fax: +31 433884151.

E-mail address: f.verheyen@molcelb.unimaas.nl (F.K. Verheyen).

${ }^{1}$ Ronald B. Driesen and Gerrit D. Dispersyn contributed equally to this paper.
}

\section{Introduction}

Cardiac fibroblasts were recently found to be functionally linked to cardiomyocytes in the sino-atrial node of the rabbit [1]. Such a heterocellular communication between fibroblasts and cardiomyocytes has been described to occur in vivo and in vitro through hemichannel-mediated coupling. In this 
process, assembly of functional gap junctions occurs when hemichannels in the plasma membrane of the fibroblast dock to those in the apposed membrane of the cardiomyocyte [2]. Until recently, it was not known whether other ways of communication exist between cardiac fibroblasts and adult cardiomyocytes, such as cell fusion, which is an essential process that contributes to a variety of biological mechanisms throughout the life of the mammalian species. The merger of plasma membranes is involved in the fertilization of the oocyte and the formation of multinuclear syncytia during the development of the mammalian placenta [3] and muscle [4]. Other events include the fusion of macrophages into multinucleated giant cells during inflammatory responses [5] and the fusion of monocytes into osteoclasts [6]. Additionally, it has been shown that adult bone marrow-derived stem cells have the ability to fuse spontaneously with neural progenitors in vitro and in vivo [7,8], with hepatocytes in the liver, Purkinje neurons in the brain and cardiac muscle in the heart. This cell fusion of bone marrow-derived hematopoietic stem cells with cardiomyocytes has also been observed at low frequency outside myocardial infarction areas [9]. Very recently, it has been described that neonatal rat cardiomyocytes fuse with various kinds of somatic cells including human umbilical vein endothelial cells, bone marrow cells, endothelial progenitor cells and cardiac fibroblasts in vitro to form heterokaryons [10].

We have designed a cellular model consisting of longterm co-cultures of adult rabbit cardiomyocytes and cardiac fibroblasts, in which typical structural characteristics of cardiomyocyte dedifferentiation could be induced. The aim of our study was to explore the dynamic, spontaneous heterocellular interactions seen between co-cultured adult fibroblasts and adult rabbit cardiomyocytes. Within this setting, we were able to determine a new kind of heterocellular communication which completely differed from the total heterocellular fusion described before. In addition, the relationship between cardiac fibroblasts and adult cardiomyocytes was investigated in the border zone of a myocardial infarction where we also found indications for close heterocellular interactions.

\section{Methods}

All experimental procedures and protocols were carried out according to the Dutch law on animal experimentation and approved by the Animal Investigation Committee of Maastricht University. The investigation conforms to the Guide for the Care and Use of Laboratory Animals published by the US National Institutes of Health (NIH Publication No. 85-23 revised 1996).

\subsection{Cell isolation and culturing conditions}

New Zealand white rabbits (ca. $2 \mathrm{~kg}$ ) were used for this study. Cardiomyocytes and cardiac fibroblasts were isolated from adult rabbits by a retrograde collagenase perfusion as previously described [11]. In brief, rabbits were anaesthetized by intra-arterial injection of $70 \mathrm{mg} / \mathrm{kg}$ pentobarbital (Sanofi, Brussels, Belgium). The heart was rapidly excised and perfused in a retrograde Langendorff mode (5 min at 35 $\mathrm{ml} / \mathrm{min}$ ) with a modified Krebs-Henseleit $(\mathrm{KRH})$ solution $\left(125 \mathrm{mM} \mathrm{NaCl}, 2.5 \mathrm{mM} \mathrm{KCl}, 1.5 \mathrm{mM} \mathrm{KH} \mathrm{PO}_{4}, 1.2 \mathrm{mM}\right.$ $\mathrm{MgSO}_{4} \cdot 7 \mathrm{H}_{2} \mathrm{O}, 10 \mathrm{mM}$ HEPES, $9.5 \mathrm{mM}$ glucose, and $5 \mathrm{mM}$ pyruvate) with $\mathrm{pH} 7.4$ at $37{ }^{\circ} \mathrm{C}$. Thereafter, fresh solution supplemented with $0.6 \mathrm{mg} / \mathrm{ml}$ collagenase (Wako, Osaka, Japan; source Clostridium histolyticum, WAQ 7317) was recirculated for $40 \mathrm{~min}$. The ventricles were gently dissociated in the same medium supplemented with 40 $\mathrm{mg} / \mathrm{ml}$ bovine serum albumin (BSA) and the cells were filtered through a nylon gauze. During three subsequent rinsing steps in fresh $\mathrm{KRH}$ solution supplemented with 10 $\mathrm{mg} / \mathrm{ml} \mathrm{BSA}$, the $\mathrm{Ca}^{2+}$ concentration was elevated to 1.4 $\mathrm{mM}$. Thereafter the cells (mainly cardiomyocytes "contaminated" with $<1 \%$ of residual cardiac fibroblasts $=$ basal co-culture) were suspended in Medium 199 (Life Technologies, Paisley, Scotland), supplemented with antibiotics (penicillin-streptomycin $0.1 \mathrm{mg} / \mathrm{ml}$ and gentamycin $2 \mu \mathrm{g} /$ $\mathrm{ml})$. The cells were seeded on laminin-coated $(10 \mu \mathrm{g} / \mathrm{ml}$; Life Technologies) glass-bottom microwell dishes (MatTek Corporation, Ashland, USA) or cover glasses in petri dishes at a low density $\left(10^{3}\right.$ cells $\left./ \mathrm{cm}^{2}\right)$ to avoid cell-cell contact. Cells were allowed to attach for $2 \mathrm{~h}$. Thereafter, fresh medium supplemented with $20 \%$ fetal bovine serum (Hyclone, Utah USA) was applied onto the cells. Cells were kept in a humidified incubator $\left(5 \% \mathrm{CO}_{2}, 37{ }^{\circ} \mathrm{C}\right)$ and the medium was replaced every other day. Because of their high proliferative capacity, rabbit cardiac fibroblasts could be passaged up to 6 times using $0.05 \%$ trypsin-EDTA (Life Technologies). 3T3 mouse fibroblasts were grown and passaged as described for the cardiac fibroblasts. Suspended cells were split $1: 3$ prior to seeding. The cardiac fibroblasts used in the cell-to-cell communication protocols were used after $1-4$ passages.

\subsection{Video time lapse microscopy}

Individual cardiomyocytes were evaluated over time using video time lapse microscopy. Six-well plates with basal co-cultures were placed onto an automatic scanning stage (stage and MAC4000 controller, Märzhäuser, Wetzlar, Germany) of an Axiovert microscope in phase contrast illumination mode (Carl Zeiss, Oberkochen, Germany) and equipped with a CCD camera. Six positions were randomly chosen in each well. At each of these positions a video image was captured every $3 \mathrm{~min}$ and stored on a disk. Each position on the 6-well plate was sequentially visited every $3 \mathrm{~min}$. Individual movies were compiled from these images. Movie processing was done using the software package SCIL-Image version 1.4 (TNOTPD, Delft, The Netherlands) on an O2 workstation (SGI, Mountain View, CA). 


\subsection{Immunocytochemistry}

For the immunocytochemical detection of connexin 43, a mouse monoclonal $\mathrm{IgG}_{1}$ antibody (Zymed, San Francisco, USA) was used. The immunocytochemical staining procedure was applied as previously described [11]. In brief, cocultures grown on coverslips were fixed with $-20{ }^{\circ} \mathrm{C}$ methanol (3 short dips) and ethanol (1 dip), air dried and kept at $-20{ }^{\circ} \mathrm{C}$ until further use. After thawing and rinsing in PBS, the cells were pretreated with PBS containing $0.1 \%$ Triton X-100 (Sigma). Cells were then rinsed $3 \times$ in PBS containing $0.5 \%$ BSA and subsequently incubated with the primary connexin 43 antibody for $1 \mathrm{~h}$ at room temperature at a 1:100 dilution. After three rinsing steps with PBS containing $0.5 \%$ BSA the coverslips were incubated for 45 min with the Cy3-labeled goat-anti-mouse secondary antibody (Jackson Immunoresearch, West Grove, USA). For a general cardiomyocyte staining, incubation with phalloidin-FITC (Sigma) was performed after detection of connexin 43, preceded and followed by three rinses in PBS. After a final rinsing step in distilled water, the coverslips were mounted with Prolong ${ }^{\mathrm{TM}}$ antifade reagent (Molecular Probes, Leiden, The Netherlands) and examined with a confocal laser scanning microscope (LSM 510, Carl Zeiss).

\subsection{Cell-cell communication protocols}

To investigate heterocellular communication between fibroblasts and adult cardiomyocytes in culture the transfer of fluorescent dye was studied [12,13]. Suspended fibroblasts were preloaded with calcein-AM (Molecular Probes, green) and Vybrant ${ }^{\mathrm{TM}}$ DiI cell labeling solution (Molecular Probes, red), according to the instructions of the manufacturer. The loading of dextran tetramethylrhodamine (MW 10 $\mathrm{kDa}$ ) neutral (Molecular Probes) was performed by scrapeloading of subconfluent adherent fibroblasts as described previously [13]. Fibroblasts were added to 1-day-old unlabeled rabbit cardiomyocyte cultures and followed for 3 days. Phosphatidylserine exposure during cell-cell contact was assessed using $200 \mu \mathrm{M}$ Alexa Green ${ }^{\mathrm{TM}_{-}}$-labeled annexin $\mathrm{V}$ (Molecular Probes) that was added to the co-culture at the moment dextran transfer was observed. Application and monitoring was done as described before [14].

\subsection{Rabbit LAD-ligation model}

New Zealand rabbits, weighing between $2-3 \mathrm{~kg}$, were used for this study. Myocardial infarction was produced by ligation of branches of the left anterior descending artery (LAD). The rabbits were anaesthetized with ketamine $(15 \mathrm{mg}$ / $\mathrm{kg}$, i.m.) and diazepam (0.5 mg/kg, i.m.). After endotracheal intubation, the rabbits were ventilated with a mixture of $\mathrm{O}_{2}$ and $\mathrm{N}_{2} \mathrm{O}$ and isofluran $1.5-2.5 \%$ whereafter an intramuscular injection of ampicilline ( $250 \mathrm{mg}$ ) was given. A twelve-lead electrocardiogram was recorded throughout the operation. A left thoracotomy was made through the fifth intercostal space and the pericardium was opened. To produce an anterior myocardial infarction, a branch of the LAD was selected for ligation. A suture was placed around the vessel, which could be tightened by a silicon tube. The selected artery was temporarily occluded and the extent of ischemia was visually and electro-cardiographically assessed for 15 min whereafter the artery was permanently ligated. After the operation procedure, the chest was closed and an intramuscular injection of buprenorfine $(0.04 \mathrm{mg} / \mathrm{kg})$ was given.

One month after creating a myocardial infarction, the rabbit heart was removed using the same procedure as described above. The rabbit heart was perfused during $5 \mathrm{~min}$ with KRH buffer containing triphenyltetrazolium chloride (Sigma) and followed by perfusion fixation with $3 \%$ glutaraldehyde buffered to $\mathrm{pH} 7.4$ with $90 \mathrm{mM} \mathrm{KH}_{2} \mathrm{PO}_{4}$ for $5 \mathrm{~min}$

\subsection{Electron microscopy}

For electron microscopical evaluation of the heterocellular contacts, co-cultures with added fibroblasts were fixed in $3 \%$ glutaraldehyde buffered with $90 \mathrm{mM} \mathrm{KH}_{2} \mathrm{PO}_{4}(\mathrm{pH}$ 7.4). After post-fixation with $2 \% \mathrm{OsO}_{4}$ (Agar Scientific LTD) in $0.1 \mathrm{M}$ sodium cacodylate buffer, impregnation was performed in 1\% uranylacetate (LADD Research Industries, Inc) in 0.1 M maleic acid (Acros) ( $\mathrm{pH}$ 5.2).

Other co-cultures were fixed in a mixture of $2 \%$

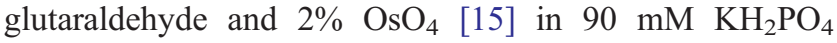
buffer ( $\mathrm{pH}$ 7.4) to improve plasma membrane contrastation. Impregnation was done in $1 \%$ uranylacetate (LADD Research Industries, Inc) in veronalacetate buffer ( $\mathrm{pH} 7.4)$. After impregnation, the co-cultures were dehydrated in graded series of ethanol and routinely embedded in Epon (LADD Research Industries, Inc).

After perfusion fixation, small biopsies, measuring $2 \mathrm{~mm}$ in diameter, were obtained from the border zone of the infarcted area and immersion fixed for at least $24 \mathrm{~h}$ with $3 \%$ glutaraldehyde buffered to $\mathrm{pH} 7.4$ with $90 \mathrm{mM} \mathrm{KH} \mathrm{KO}_{4}$. Thereafter, the samples were washed in the same buffer for $24 \mathrm{~h}$ and postfixed for $1 \mathrm{~h}$ in $2 \% \mathrm{OsO}_{4}$ buffered to $\mathrm{pH} 7.4$ with veronalacetate. Next, the samples were rapidly dehydrated through a graded ethanol series and routinely embedded in Epon (LADD Research Industries, Inc.).

Ultrathin sections of the co-cultures and from biopsies of the rabbit heart tissue were counterstained with uranium acetate and lead citrate, prior to examination in a Philips CM100 electron microscope.

\section{Results}

\subsection{Fibroblasts induce a phenotypic adaptation of cardiomyocytes}

Video time lapse microscopy revealed dynamic fibroblast activities in basal co-cultures. While migrating through the 

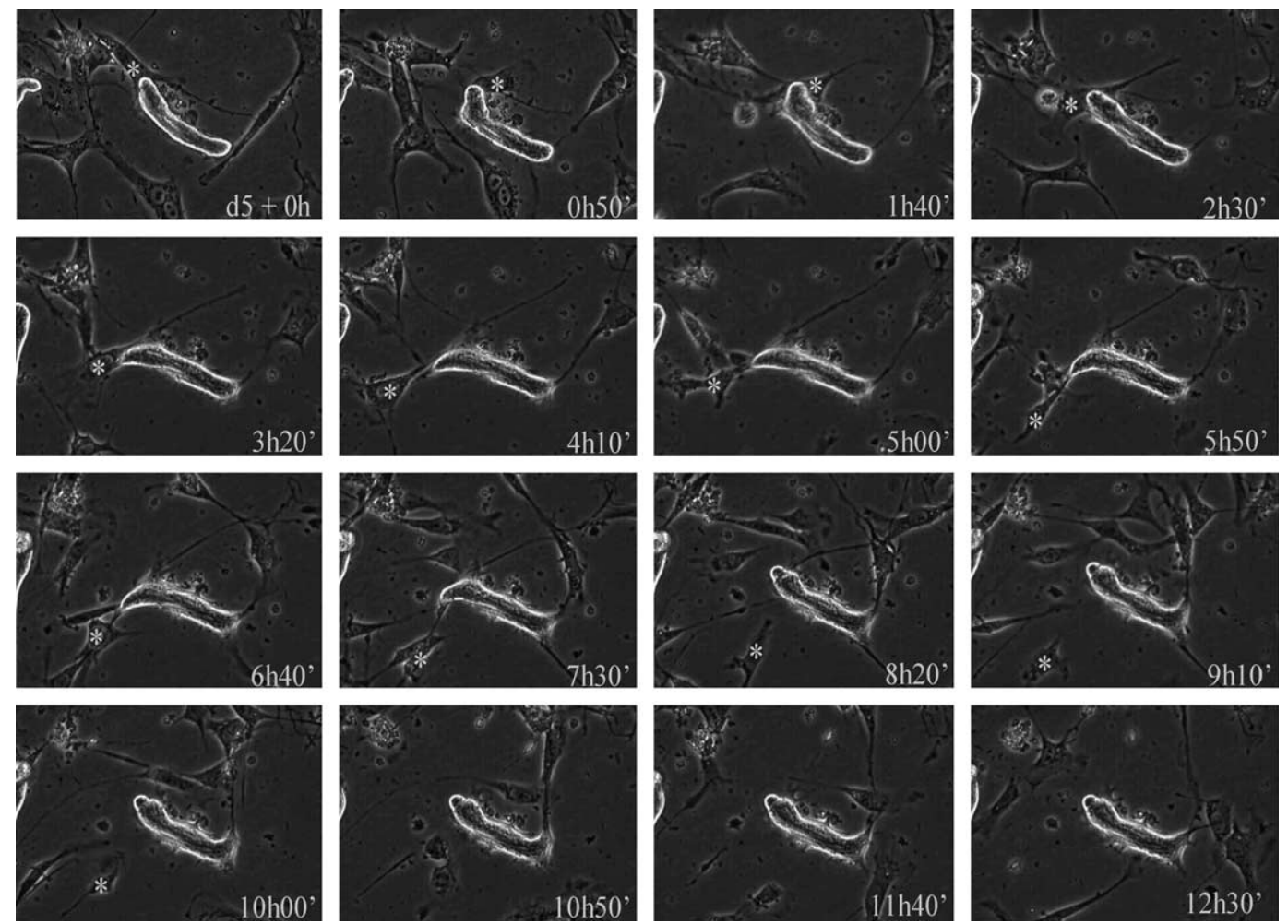

Fig. 1. Video time lapse microscopy of the interaction between a moving fibroblast (asterisk) and a cardiomyocyte in a day 5 co-culture. The sequential images were taken over a 12.5-h time period. Note that the cardiomyocyte is being pulled at in different directions before detachment of the fibroblast. The time lapse sequence can be viewed at the website of Cardiovascular Research.

petri dish, the fibroblasts interacted spontaneously with each other as well as with cardiomyocytes. Due to the low number of residual fibroblasts in the first 2 days of coculture, only $5 \%$ of the cardiomyocytes developed contacts with fibroblasts. The number of contacts increased to $25 \%$ after 5 days of co-culture, most likely related to the observed increase in fibroblast proliferation. The early contacts with the rectangular-shaped cardiomyocytes occurred mainly, but not exclusively, at the distal ends of the cardiomyocyte. Cell contact was not immediately lost when a fibroblast migrated away from a cardiomyocyte after having been in close apposition. The pulling forces generated caused a profound local extension of the cardiomyocyte. Such an individual cell-cell contact with subsequent extensive pulling could last up to $7 \mathrm{~h}$ in duration (Fig. 1; the movie showing these time lapse sequences can be viewed at the website of Cardiovascular Research). These results were not only obtained with autologous rabbit fibroblasts but similarly with mouse 3T3 fibroblasts that were added to the culture. These cellular interactions between cardiomyocytes and fibroblasts were rapidly followed by profound phenotypic adaptation of the myocyte resembling dedifferentiation. The spreading of the cell coincided with a gradual loss of crossstriation due to sarcomeric depletion.
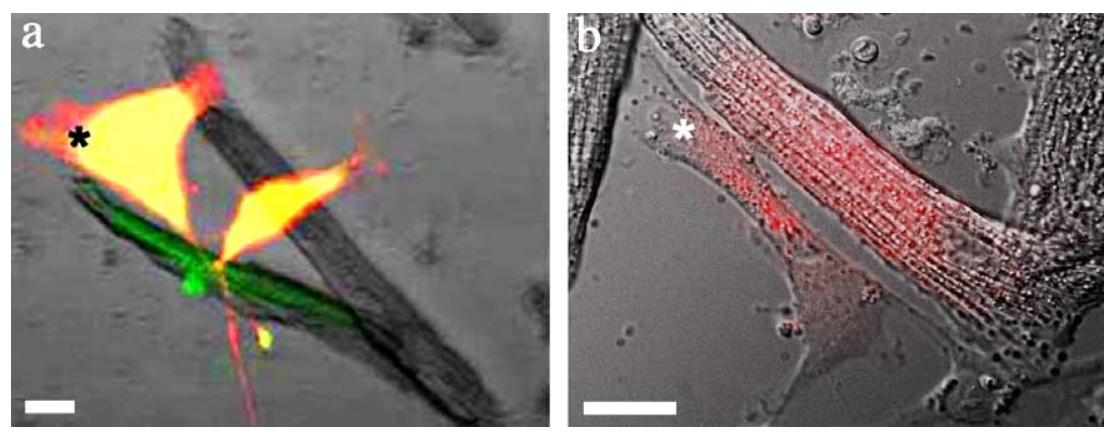

Fig. 2. a-b. Vital imaging: overlay of differential interference contrast and fluorescent images. a. Prelabeling of the fibroblast (asterisk) with calcein (green) and the plasma membrane with DiI (red) shows the cell in overlay as yellow. Co-cultivation for $1.5 \mathrm{~h}$ results in contacting of the prelabeled fibroblasts with the unlabeled cardiomyocyte and the transfer of only calcein (green fluorescence) to this cardiomyocyte. b. Transfer of dextran $10 \mathrm{kDa}$ (red) from a scrape-loaded fibroblast to the cardiomyocyte is detected $48 \mathrm{~h}$ after co-culturing. Scale bars represent $20 \mu \mathrm{m}$. 


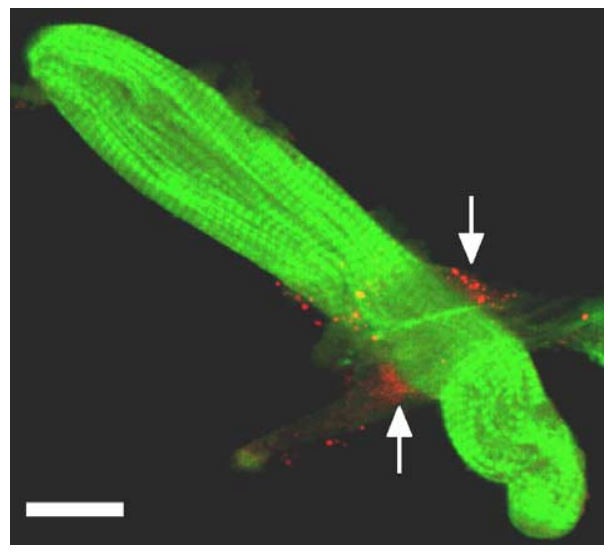

Fig. 3. Connexin 43 organization at the fibroblast-cardiomyocyte contact sites. Arrows point to the red dot-like staining of the contact area with anticonnexin 43. The cardiomyocyte is counterstained using Phalloidin-FITC (green) staining sarcomeric actin. Scale bar represents $20 \mu \mathrm{m}$.

\subsection{Dedifferentiation-related heterocellular communication}

Heterocellular communication between fibroblasts and cardiomyocytes was assessed by dye transfer experiments. Fibroblasts were preloaded with calcein-AM (MW 994.87 Da; cytoplasmic localization) and DiI (incorporating into the plasma membrane) or with dextran tetramethylrhodamine (MW $10 \mathrm{kDa}$; cytoplasmic localization) before adding them to cultures of 1-day-old unlabeled cardiomyocytes. Approximately $1.5 \mathrm{~h}$ after addition of the fibroblasts, dispersed green fluorescent cytoplasmic calcein label became detectable in some cardiomyocytes in contact with fibroblasts (Fig. 2a). As the number of fibroblast-cardiomyocyte interactions increased over time, a larger number of green fluorescent calcein-containing cardiomyocytes could be detected in the following few hours. Not all cardiomyocytes in close contact with loaded fibroblasts became calcein-positive. Also, after approximately $4.5 \mathrm{~h}$, isolated fluorescent myocytes lacking fibroblast apposition were noticed, indicating the transient nature of the interaction. DiI-positive cardiomyocytes were not observed for up to $24 \mathrm{~h}$ after the addition of preloaded fibroblasts. Transfer of the high molecular weight dextran rhodamine (MW $10 \mathrm{kDa}$ ) from fibroblasts towards spreaded cardiomyocytes became visible not until 2 days after addition of labeled (rabbit or mouse 3T3) fibroblasts (Fig. 2b). Dispersed cardiomyocyte labeling was more frequently seen 3 days after addition and again labeled cells without fibroblast contacts were sometimes encountered. The affected cardiomyocytes always showed spreading, indicating phenotypic adaptation, i.e. dedifferentiation. Addition of dextran rhodamine to the culture medium of cardiomyocytes did not result in any uptake of the dye by the cardiomyocytes. Immunocytochemistry performed on 1.54.5-h-old co-cultures revealed a diffuse or punctate pattern of connexin 43 that was regularly present at the interface between a fibroblast and a myocyte (Fig. 3). A strand-like connexin 43 organization was never found.

Small dot-like annexin V label was present at some but not all of the contact sites between fibroblasts and cardiomyocytes (Fig. 4a). Especially the areas where cardiomyocytes were touched by pseudopodia-like extensions of a fibroblast were positive. In a co-labeling experiment, concomitant dextran and annexin $\mathrm{V}$ positivity was occasionally observed (Fig. 4b). Formation of heterokaryons between fibroblasts and cardiomyocytes were not observed at any time period of co-cultivation.

\subsection{Ultrastructural evidence of heterocellular communica- tion in vitro}

In the electron microscope, most of the contact areas between fibroblast and cardiomyocyte plasma membranes after $3 \mathrm{~h}$ in co-culture were mere close appositions without obvious membrane specialisations (not shown). However, after $48 \mathrm{~h}$ in co-culture, several small-sized (100-500 $\mathrm{nm}$ in length) heterocellular contact areas were detected showing fusion of the heterocellular plasma membranes and resulting in direct cytoplasmic contact between the cells (Fig. 5a-e). Signs of plasma membrane
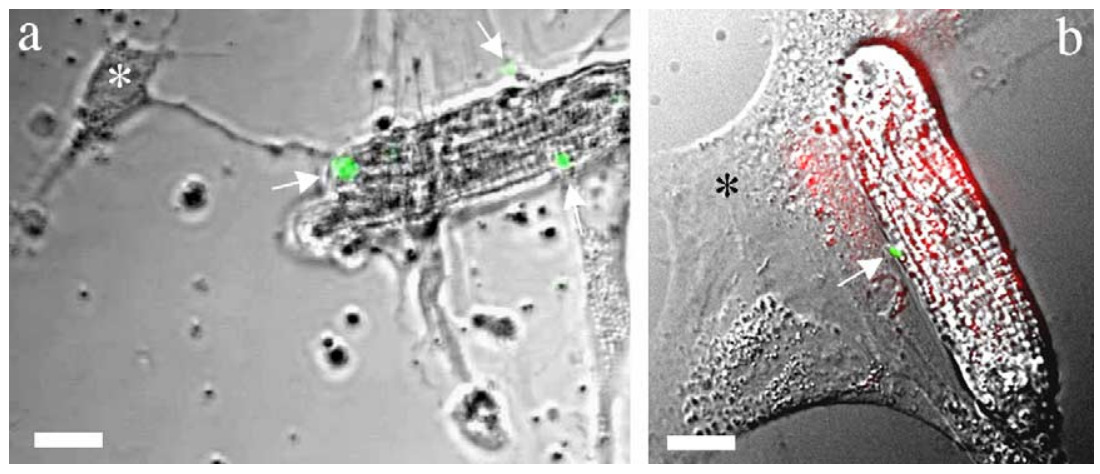

Fig. 4. a-b. Vital imaging: overlay of differential interference contrast and fluorescent images. a. Phosphatidylserine (PS) exposure at contact sites of fibroblast pseudopodia and cardiomyocytes results in Alexa Green ${ }^{\mathrm{TM}}$-Annexin V labeling. b. Concomitant labeling of PS exposure by Alexa Green ${ }^{\mathrm{TM}}$-Annexin V (green) at a heterocelllular contact site (arrow) and transfer of dextran 10kDa (red) from the prelabeled fibroblast (asterisk) to the cardiomyocyte. Scale bars represent $20 \mu \mathrm{m}$. 

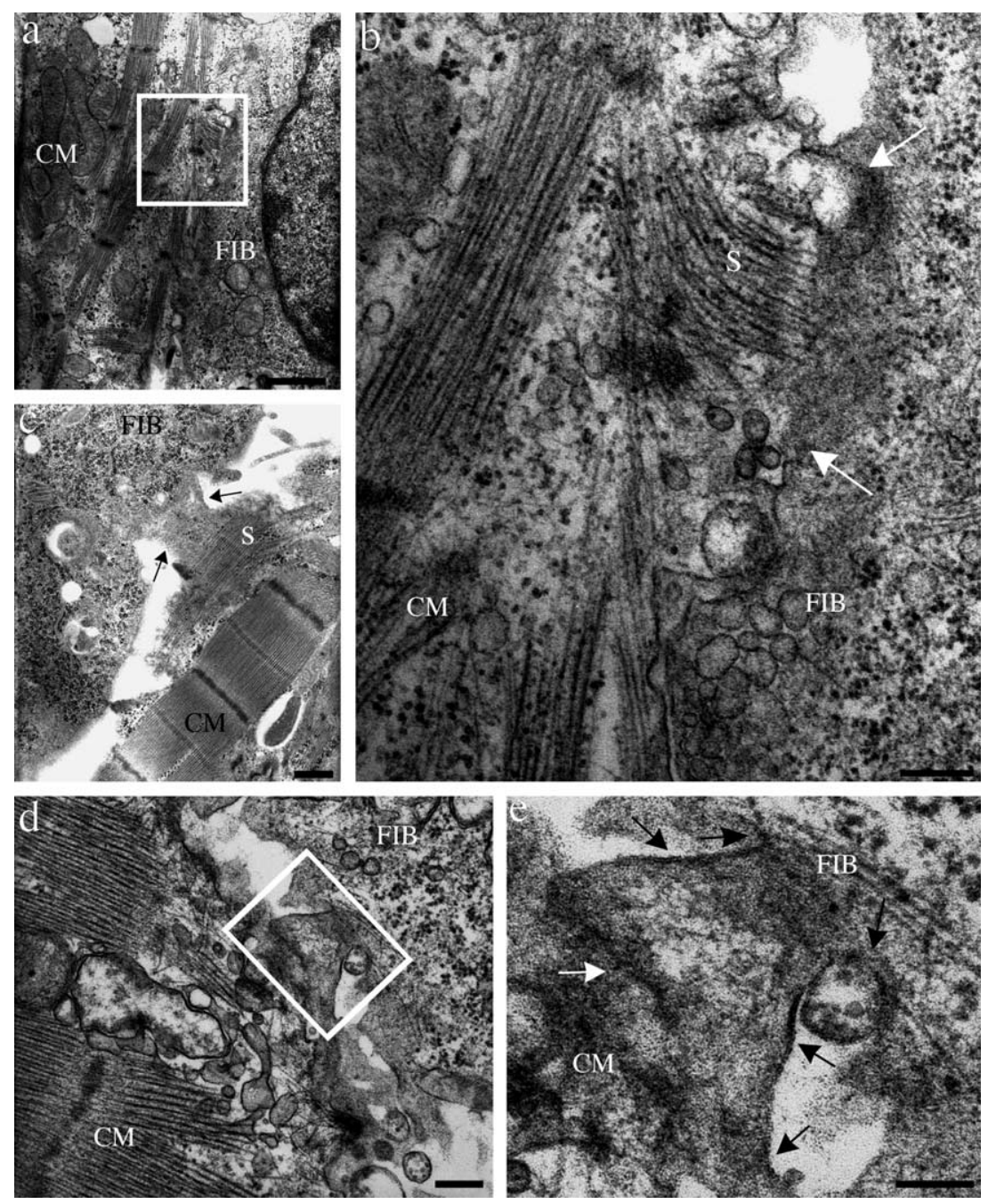

Fig. 5. a-e. Electron microscopy: fusional contacts and hemifusion observed in vitro. (a) Overview of a 3 T3 fibroblast (right, FIB) in firm contact with a dedifferentiated cardiomyocyte (left, CM). The dedifferentiation is evidenced by the disruption of the sarcomere structure (myolysis) and the accumulation of glycogen particles (black dots in the cytoplasm). (b) Higher magnification of the white box area: in the contact zone between the white arrows, membrane separation between the cells is absent. The sarcomeric filaments (S) are bent to the fibroblast cytoplasm. (c) Contact area between a 3T3 fibroblast (upper left, FIB) and a cardiomyocyte (bottom right, CM; note sarcomeric structure=S). A partial cell fusion between both cell types is evident, as indicated by the arrows. (d) Electron microscopic overview of a $3 \mathrm{~T} 3$ mouse fibroblast (upper right, FIB) making a fusional contact (boxed area) with a dedifferentiating cardiomyocyte (left, CM). (e) Higher magnification of the boxed area: the outer plasma membrane bilayer of the fibroblast is fused with the plasma membrane bilayer of the cardiomyocyte (black arrows); at the white arrow, only one bilayer of a (plasma) membrane separates a part of both adjoining cells suggesting hemifusion. a, b, d and e: Chang fixation; c: glutaraldehyde fixation followed by $\mathrm{OsO}_{4}$. Scale bars: $2 \mu \mathrm{m}$ (a); $500 \mathrm{~nm}$ (b); $500 \mathrm{~nm}$ (c); $200 \mathrm{~nm}(\mathrm{~d})$; and $100 \mathrm{~nm}$ (e).

hemifusion as indicated by the presence of one bilayer separating parts of both cells were sometimes encountered (Fig. 5e). The cardiomyocytes fused with fibroblasts always showed signs of dedifferentiation as verified by myolysis, patchy distribution of heterochromatin in the nucleus, the presence of increased amounts of glycogen and changes in mitochondrial morphology. Occasionally, also larger-sized heterocellular fusional contacts up to 6 $\mu \mathrm{m}$ in length were observed between fibroblasts and myocardial cells, which were in an advanced stage of dedifferentiation. Ultrastructural hallmarks of apoptosis, i.e. defragmentation of the nucleus, condensation of the heterochromatin, densification of the cytoplasm and bleb formation, were never observed in the dedifferentiated cardiomyocytes.

\subsection{Ultrastructural evidence of heterocellular interactions in the heart}

Several close contacts between dedifferentiated cardiomyocytes and fibroblasts could be verified in the border zone of infarct areas of the rabbit heart. The heterocellular linkage sites between cardiomyocytes and fibroblasts might be categorized into three consecutive stages: close apposition with still intact basal lamina of the cardiomyocyte (Fig. 6a), local disruption of the cardiomyocyte basal lamina and 

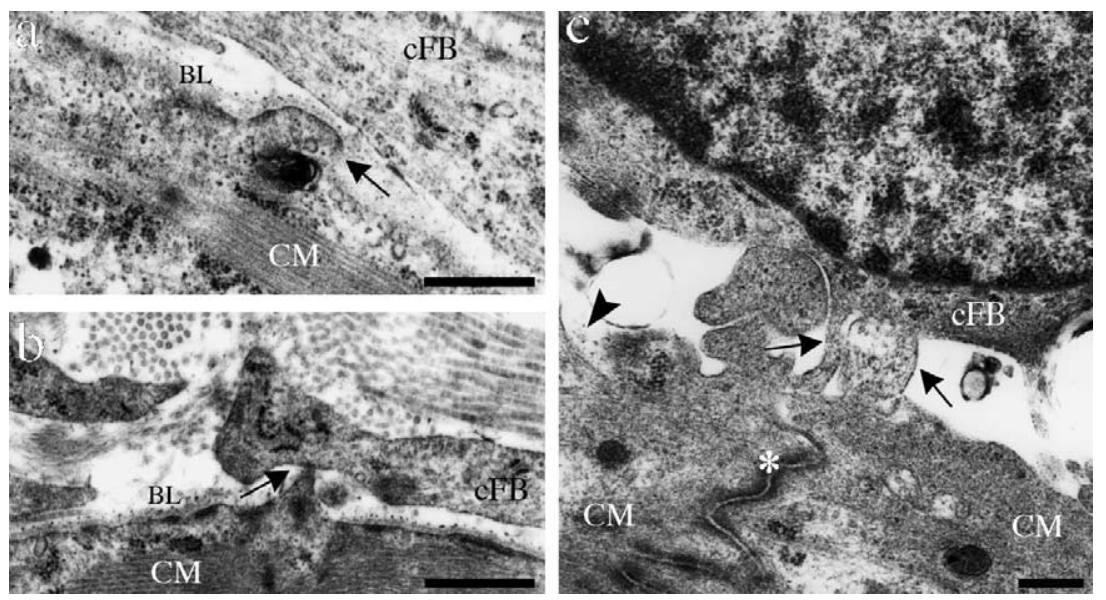

Fig. 6. a-c. Electron microscopic images of the stages suggested to be involved in the formation of heterocellular contacts between cardiac fibroblasts (cFB) and dedifferentiating cardiomyocytes (CM) in the border zone of an infarcted area of the rabbit heart. (a) An extension of the cardiomyocyte plasma membrane (arrow) is reaching to the plasma membrane of the cardiac fibroblast. The basal lamina (BL) of the cardiomyocyte is still intact. (b) A protrusion of the cardiomyocyte (arrow) reaches to the plasma membrane of the cardiac fibroblast. The myocyte basal lamina (BL) is disrupted at the site of protrusion. (c) Heterocellular connections (arrows) are seen between a cardiac fibroblast and two cardiomyocytes; the latter are connected to each other by an intercalated disc (asterisk). Only a small remnant of the basal lamina (arrowhead) is present on the plasma membrane of the cardiomyocytes. Scale bars: $500 \mathrm{~nm}$ (a and b) and $200 \mathrm{~nm}(\mathrm{c})$.

protrusion toward the fibroblast plasma membrane (Fig. 6b), and firm connection between the cell types (Fig. 6c). Close or firm heterocellular contacts with disruption of basal laminae were not seen in the normal, non-infarcted tissue.

\section{Discussion}

We have studied a co-culture system of adult rabbit cardiomyocytes and fibroblasts in which cardiomyocyte dedifferentiation could be mimicked. It was evidenced that dedifferentiation only occurred in cardiomyocytes which were in close contact to fibroblasts [11]. In the course of this study we have elucidated the nature of the fibroblastcardiomyocyte interactions. The results indicate a spontaneous and very dynamic heterocellular interaction leading, on the one hand, to the phenotypic adaptation of the cardiomyocyte and, on the other hand, to a dual way of heterocellular communication which appeared to be related to the stage of phenotypic adaptation. This adaptation was accompanied by heterocellular communication via functional gap junctions (early phenomenon) and via unexpected partial cell fusion (late phenomenon) in a specific chronological order. The video time lapse experiments clearly showed that only cardiomyocytes that have been extensively 'pulled at' by neighboring fibroblasts undergo the typical flattening, a response that has been identified as the first obvious change into cardiomyocyte dedifferentiation in vitro [11]. Conversely, cardiomyocytes that did not undergo these dynamic interactions with fibroblasts did also not undergo such shape changes. It is obvious that the 'pulling' by the fibroblasts imposed to the cardiomyocytes subjects these to mechanical load, i.e. passive stretch.
In our in vitro setting, the passive stretch invoked by the pulling of fibroblasts might not be the sole trigger for the dedifferentiation since an early communication via heterocellular plasma membrane configuration was suggested by the observation of calcein dye transfer from preloaded fibroblasts to cardiomyocytes. This dye transfer appeared to be selective since not all cardiomyocytes in close contact with loaded fibroblasts were found calcein-positive. This indicates that leakage of calcein out of fibroblasts with subsequent uptake by cardiomyocytes is not likely.

It is described previously that cardiac fibroblasts can be electrically coupled to neonatal rat cardiomyocytes in vitro [16-18], most evidently through heterologous gap junction channels allowing the passage of molecules smaller than 1000 MW. Electron microscopical analysis of our 3-h-old co-cultures revealed anchoring of small parts of fibroblast protrusions to the cardiomyocytes. Although immunocytochemistry revealed dot-like connexin 43 positivity at fibroblast-cardiomyocyte contacts, typical gap junctional plaque structures were not observed. Similar observations were recently described in vitro [17] and in vivo [1].

These results suggest the presence of functional connexin 43 hemichannels (or connexons), which are the building blocks of the gap junction plaque and are described to be present on the plasma membrane of isolated rabbit ventricular cardiomyocytes $[19,20]$ and on cardiac fibroblasts [21]. Each hemichannel is randomly inserted into the plasma membrane and migrates to the site of cell-cell contact before docking with the neighbouring cells' hemichannel to form a communicating connexon bridge [22]. A functional gap junction is consequently formed by accretion of connexin 43 hemichannels [23] as has most likely occurred early in our co-cultures, thereby allowing small molecular dye transfer from fibroblasts to adult type 
cardiomyocytes. The fact that a morphological equivalent of a typical gap junction could not be verified in vivo possibly relates to the transient nature of the communication and/or the small number of individual connexons formed [24]. DiI transfer from the fibroblast to the cardiomyocyte plasma membrane was not observed for up to $24 \mathrm{~h}$ after the addition of preloaded fibroblasts, indicating a lack of functional events between the heterocellular plasma membranes, at least within this time frame.

Transfer of the high molecular weight dextran tetramethylrhodamine (MW $10 \mathrm{kDa}$ ) occurred from $48 \mathrm{~h}$ after addition of preloaded cardiac or mouse fibroblasts onwards. In addition, the transfer was only seen in cardiomyocytes in an ongoing stage of dedifferentiation. Thus, phenotypic adaptation appeared to be a prerequisite for this second way of heterocellular communication. Apparent release of the dextran probe into the culture medium was never observed and dextran-positive vesicles indicating endocytosis were not seen either. Because of the size of the dextran tracer molecule and its diffuse distribution in the cardiomyocyte, it is more likely that intercellular transfer of these molecules occurred via pores that resulted from partial cell fusion. Electron microscopic observations indeed confirmed the occurrence of partial cell fusion between fibroblasts and cardiomyocytes, allowing open cytoplasmic communication. Apart from the open connections hemifusional contacts were also sometimes observed. Such hemifusion can represent an earlier stage in the process of partial cell fusion as described before [25]. Again, the ultrastructural examination showed the dedifferentiated appearance of interacting cardiomyocytes. In an earlier study [14] we reported that membrane fusion during myotube formation is accompanied by transient phosphatidylserine (PS) exposure at the outer surface of the myoblast cells, a phenomenon that can be monitored by means of annexin $\mathrm{V}$ affinity to PS. When applied to our allogeneic cell cultures, a dot-like annexin $\mathrm{V}$ labeling pattern became obvious at part of the contact sites between fibroblasts and cardiomyocytes. Specifically, the areas where cardiomyocytes were touched by pseudopodia-like extensions of a fibroblast showed these annexin $\mathrm{V}$ positive fluorescent clusters. Since PS exposure has also been recognized as a hallmark of apoptotic cells we examined our cells for characteristic features of programmed cell death. No characteristics of apoptosis were ever detected in our ultrastructural studies thereby excluding the possibility that the annexin $\mathrm{V}$ positivity was suggestive for the initiation of this cell death process. In a co-labeling experiment, concomitant dextran transfer and annexin $\mathrm{V}$ positivity could be observed indicating that the trigger for such a partial cell fusion is likely to be PS translocation from the inner to the outer leaflet of the plasma membrane. Since 3T3 mouse fibroblasts can also become involved in such fusional contacts with rabbit cardiomyocytes, the phenomenon is apparently not restricted to autologous cells. The size of the contact openings (100 $\mathrm{nm}$ up to even $6 \mu \mathrm{m}$ ) indicates the possibility of transfer of very large cytoplasmic components and further represents a form of low-resistance heterocellular communication. It is known that cardiac fibroblasts are electrically 'non-excitable' cells (i.e. they do not respond to an electrical stimulus with generation of an action potential), but they are efficient mechano-electrical transducers [26]. It has previously been shown that cardiac fibroblasts can synchronize the electrical activity between adjacent cardiomyocytes in vitro. This synchronization process is associated with local conduction delays suggesting indeed a higher resistance communication at the heterocellular contact places [17]. The direct cytoplasmic connections seen during partial cell fusion might lead to a lower resistance communication between the fibroblast and the cardiomyocyte but any further documentation on this is lacking and needs additional examination.

The concept of partial heterocellular fusion provides a unique opportunity for the mere transfer of cytoplasmic components without incorporation of the donor nucleus into the acceptor cell as described recently for the fusion between cardiomyocytes and bone marrow-derived cells [7]. Indeed, cells can be genetically engineered to express certain proteins, such as transcription factors, which can subsequently be transported to other cells [27]. This intercellular transport of transcription factors is commonly effected by plants via so-called plasmodesmata $[28,29]$. A similar conclusion was recently drawn based on the observation of intercellular organelle transport through nanotubular structures amongst PC12 cells [30].

More specifically for the heart, donor cells may be engineered to express cardiomyocyte-specific proteins. For example, ex vivo cardiac fibroblast cardiomyoplasty is a combination of genetic and tissue engineering of cardiac rat fibroblasts which are transfected to express the musclespecific MyoD [31]. The MyoD family of transcription factors is able to induce myogenesis in cardiac fibroblasts or other cells. In our co-cultures, fusional contacts were particularly obvious between donor fibroblasts and dedifferentiated myocardial cells.

Therefore, such dedifferentiated hibernating cells, known to be present in the border zone of an infarct area and in ventricular or atrial tissue in other cardiac diseases [32-35], could very well be the target for heterocellular communication. This assumption is reinforced by the observation of close contacts between cardiac fibroblasts and dedifferentiating cardiomyocytes in the border zone of a myocardial infarcted area of the rabbit heart. Most likely, these contacts can occur due to the (local) disruption of the basal lamina of the cardiomyocyte. Such a disruption of the basal lamina is one of the characteristics seen in dedifferentiated (hibernating) cardiomyocytes, a phenomenon that is not observed in normal adult cardiomyocytes. Whether these close contacts also represent heterocellular partial fusions remains to be determined. Complete cell fusion with the formation of heterokaryons has recently been described between cardiomyocytes and transplanted endogenous cells including 
human umbilical vein endothelial cells and skeletal musclederived cells at the border zone of injured heart tissue but not in normal areas [10]. Close contacts between cardiomyocytes and interstitial cells were also seen at the border of injured and healing rat myocardium [36].

Structural and gap junctional remodeling have been described in biopsies taken from humans with a history of previous infarction and subsequent left ventricular dysfunction [37] and in atria of goats during atrial fibrillation [38]. In both pathological conditions a progressive reduction and disruption of connexin 43 gap junctions has been described in hibernating tissue which could lead to abnormal impulse propagation between hibernating cardiomyocytes and could possibly be associated with electromechanical dysfunction. Whether cardiac fibroblasts can couple to the hibernating cardiomyocytes in vivo through partial cell fusion and thereby influence the propagation properties of the dedifferentiated cardiomyocytes is currently unknown.

Our results on partial cell fusion in co-culture and the detection of close heterocellular contacts in the border zone of a myocardial infarction invite for further research into the occurrence of partial cell fusion in vivo and the application of this phenomenon in new therapeutic strategies dealing with, amongst others, myocardial pathologies.

\section{Acknowledgements}

The authors thank Marie-Hélène Lenders, Mieke Henfling, Menno Knetsch, Peter Kelderman and Bert Schutte for technical assistance and Chris Reutelingsperger for advice in the preparation of the manuscript. We acknowledge financial support for vital imaging equipment by NWO/ZonMW (grant nr. 901-28-134).

\section{Appendix A. Supplementary data}

Supplementary data associated with this article can be found, in the online version, at doi:10.1016/j.cardiores. 2005.05.020.

\section{References}

[1] Camelliti P, Green CR, LeGrice I, Kohl P. Fibroblast network in rabbit sinoatrial node. Structural and functional identification of homogeneous and heterogeneous cell coupling. Circ Res 2004;94:828-35.

[2] Li H, Liu TF, Lazrak A, Peracchia C, Goldberg GS, Lampe PD, et al. Properties and regulation of gap junctional hemichannels in the plasma membranes of cultured cells. J Cell Biol 1996;134:1019-30.

[3] Kliman H, Nestler J, Sermasi E, Sanger J, Strauss J. Purification, characterization and in vitro differentiation of cytotrophoblasts from human term placentae. Endocrinology 1986;118:1567-82.

[4] Kalderon N, Gilula NB. Membrane events involved in myoblast fusion. J Cell Biol 1979;81:411-25.

[5] Kraus B. Formation of giant cells in vivo. Immunobiology 1982;161: $290-7$.
[6] Severson AR. Differentiation of mononuclear cells into multinucleated osteoclast-like cells. Exp Cell Biol 1983;51:267-74.

[7] Alvarez-Dolado M, Pardal R, Garcia-Verdugo JM, Fike JR, Lee HO, Pfeffer K, et al. Fusion of bone marrow-derived cells with Purkinje neurons, cardiomyocytes and hepatocytes. Nature 2003;425:968-73.

[8] Vassilopoulos G, Wang P, Russell DW. Transplanted bone marrow regenerates liver by cell fusion. Nature 2003;422:901-4.

[9] Nygren JM, Jovinge S, Breitbach M, Säwen P, Röll W, Hescheler J, et al. Bone marrow-derived hematopoietic cells generate cardiomyocytes at a low frequency through cell fusion, but not transdifferentiation. Nat Med 2004;10:494-501.

[10] Matsuura K, Wada H, Nagai T, Iijima Y, Minamino T, Sano M, et al. Cardiomyocytes fuse with surrounding noncardiomyocytes and reenter the cell cycle. J Cell Biol 2004;167:351-63.

[11] Dispersyn GD, Geuens E, Ver Donck L, Ramaekers FCS, Borgers M. Adult rabbit cardiomyocytes undergo hibernation-like dedifferentiation when co-cultured with cardiac fibroblasts. Cardiovasc Res 2001;51:230-40

[12] Goldberg GS, Bechberger JF, Naus CCG. A pre-loading method of evaluating gap junctional communication by dye transfer. BioTechniques 1995;18:490-7.

[13] Mc Neil PL, Murphy RF, Lanni F, Taylor Lansing D. A method for incorporating macromolecules into adherent cells. J Cell Biol 1984;98:1556-64.

[14] van den Eijnde SM, van den Hoff MJB, Reutelingsperger CPM, van Heerde WL, Henfling MER, Vermeij-Keers C, et al. Transient expression of phosphatidylserine at cell-cell contact areas is required for myotube formation. J Cell Sci 2001;114:3631-42.

[15] Chang JH. Fixation and embedment, in situ, of tissue culture cells for electron microscopy. Tissue Cell 1972;4:561-74.

[16] Rook MB, van Ginneken CG, de Jonge B, El Aoumari A, Gros D, Jongsma HJ. Differences in gap junction channels between cardiac myocytes, fibroblasts, and heterologous pairs. Am J Physiol 1992;263:C959-77.

[17] Gaudesius G, Miragoli M, Thomas SP, Rohr S. Coupling of cardiac electrical activity over extended distances by fibroblasts of cardiac origin. Circ Res 2003;93:421-8.

[18] Kohl P. Heterogeneous cell coupling in the heart: an electrophysiological role for fibroblasts. Circ Res 2003;93:381-3.

[19] John S, Cesario D, Weiss JN. Gap junctional hemichannels in the heart. Acta Physiol Scand 2003;179:23-31.

[20] Scott AJ, Kondo R, Wang SY, Goldhaber JI, Weiss J. Connexin-43 hemichannels opened by metabolic inhibition. J Biol Chem 1999;274: 236-40.

[21] Kondo R, Wang SY, John SA, Weiss JN, Goldhaber JI. Metabolic inhibition activates a non-selective current through connexin hemichannels in isolated ventricular myocytes. J Mol Cell Cardiol 2000;32: $1859-72$.

[22] Gaietta G, Deerinck TJ, Adams SR, Bouwer J, Tour O, Laird DW, et al. Multicolor and electron microscopic imaging of connexin trafficking. Science 2002;296:503-7.

[23] Evans WH, Martin PE. Gap junctions: structure and function. Mol Membr Biol 2002;19:121-36.

[24] De Mazière AMGL, van Ginneken ACG, Wilders R, Jongsma HJ, Bouman LN. Spatial and functional relationship between myocytes and fibroblasts in the rabbit sinoatrial node. J Mol Cell Cardiol 1992; 24:567-78

[25] Cohen FS, Melikyan GB. The energetics of membrane fusion from binding, through hemifusion, pore formation and pore enlargement. J Membr Biol 2004;199:1-14.

[26] Camelliti P, Devlin GP, Matthews KG, Kohl P, Green CR. Spatially and temporally distinct expression of fibroblast connexins after sheep ventricular infarction. Cardiovasc Res 2004;62:415-25.

[27] Prochiantz A, Joliot A. Can transcription factors function as cell-cell signaling molecules. Nat Rev Mol Cell Biol 2003;4:814-9.

[28] Zambryski P, Crawford K. Plasmodesmata: gatekeepers for cell-to-cell transport of developmental signals in plants. Annu Rev Cell Dev Biol 2000;16:393-421. 
[29] Heinlein M. Plasmodesmata: dynamic regulation and role in macromolecular cell-to-cell signaling. Curr Opin Plant Biol 2002;5:543-52.

[30] Rustom A, Saffrich R, Markovic I, Walther P, Gerdes H-H. Nanotubular highways for intercellular organelle transport. Science 2004; 303:1007-10.

[31] Etzion S, Barbash IM, Feinberg MS, Zarin P, Miller L, Guetta E, et al. Cellular cardiomyoplasty of cardiac fibroblasts by adenoviral delivery of MyoD ex vivo: an unlimited source of cells for myocardial repair. Circulation 2002;106:I125-30.

[32] Sharov VG, Sabbah HN, Ali AS, Shimoyama H, Lesch M, Goldstein $\mathrm{S}$. Abnormalities of cardiocytes in regions bordering fibrous scars of dogs with heart failure. Int J Cardiol 1997;60:273-9.

[33] Thijssen VL, Ausma J, Liu GS, Allessie MA, van Eys GJ, Borgers M. Structural changes of atrial myocardium during chronic atrial fibrillation. Cardiovasc Pathol 2000;9:17-28.

[34] Dispersyn GD, Mesotten L, Meuris B, Maes A, Mortelmans L, Flameng W, et al. Dissociation of cardiomyocyte apoptosis and dedifferentiation in infarct border zones. Eur Heart J 2002;23: $849-57$.

[35] Thomas SA, Fallavollita JA, Suzuki G, Borgers M, Canty Jr JM. Dissociation of regional adaptations to ischemia and global myolysis in an accelerated swine model of chronic hibernating myocardium. Circ Res 2002;91:970-7.

[36] Vracko R, Thorning D, Frederickson RG, Cunningham D. Myocyte reactions at the borders of injured and healing rat myocardium. Lab Invest 1988;59:104-14.

[37] Kaprielian RR, Gunning M, Dupont E, Sheppard MN, Rothery SM, Underwood R, et al. Downregulation of immunodetectable connexin43 and decreased gap junction size in the pathogenesis of chronic hibernation in the human left ventricle. Circulation 1998; 27:651-60

[38] Ausma J, Litjens N, Lenders M-H, Duimel H, Mast F, Wouters L, et al. Time course of atrial fibrillation-induced cellular structural remodeling in atria of the goat. J Mol Cell Cardiol 2001;33:2083-94. 